\title{
Personality traits and health behaviors as predictors of subjective wellbeing among a multiethnic sample of university-attending emerging young adults
}

\author{
Chia-Hsin Emily Cheng · Jie W Weiss · Judith M Siegel
}

\begin{abstract}
This study examines the relative contributions of individual characteristics of personality and health behaviors to subjective wellbeing among university-attending emerging young adults. Three dimensions of wellbeing were assessed: affective (positive affect), physical/mental (overall health), and cognitive (quality of life). The sample ( $\mathrm{N}=599)$ consisted of students of various racial/ethnic backgrounds, including White/non-Hispanic, Hispanic/Latino, Asian/Pacific Islander, and Black/African American from a large public university in Southern California ( $28 \%$ male, $72 \%$ female; mean age $=20.85, S D=1.84)$. Respondents completed the Student Health Survey, which consisted of items on basic demographics, substance use, health behaviors, Affect Balance Scale, Extraversion and Neuroticism subscales of the Big Five Taxonomy of Personality, Quality of Life scale, and an online food-intake survey for seven days. Descriptive statistics and bivariate correlations were calculated as preliminary analysis and hierarchical regression analyses were conducted to examine how each set of predictors contributes to the overall predictive ability and relative importance on subjective wellbeing. Extraverted individuals reported more positive affect and higher quality of life. Neuroticism was associated with less positive affect, poorer health, and lower quality of life. Physical activity was consistently associated with subjective wellbeing, accounting for $33 \%, 13 \%$, and $32 \%$ of the total variance in positive affect, overall health, and quality of life, respectively. Findings indicate that health behaviors are important correlates of three dimensions of wellbeing over and above the effects of personality traits. Implications for designing health and wellness programs to improve the wellbeing and quality of life among young adults are discussed.
\end{abstract}

Keywords: college students, health behaviors, personality, wellbeing, emerging adulthood, physical activity.

\section{Introduction}

There has been increased national interest in health research on wellbeing, which is defined as positive aspects of individual functioning and global life satisfaction. The Centers for Disease Control and Prevention (CDC) Health-Related Quality of Life Program focuses on how wellbeing can be integrated into health promotion and measured in public health surveillance (CDC, 2009). One of the new topic areas of Healthy People 2020 is health-related quality of life and wellbeing (USDHHS, 2010), and an overarching goal of Healthy Campus 2020 is to promote quality of life, healthy development, and positive health behaviors on college campuses (American College Health Association, 2012). Because individual wellbeing is entwined with physical and mental health, there is a need to better understand health determinants and outcomes beyond simple measures of morbidity and mortality. Although over 19 million people in the U.S. are college- 
attending young adults who generally are in better health than non-college students (US Census, 2011), more research is needed to understand the factors that contribute to their wellbeing.

Indicators of wellbeing include happiness, affect, life satisfaction, and quality of life (Diener, 2000; Pressman \& Cohen, 2005), and wellbeing is associated with both physical and mental health (Diener \& Seligman, 2004; Diener, Suh, Lucas, \& Smith, 1999; Dunn, 1973; Pressman \& Cohen, 2005). In addition, lifestyle health behaviors affect an individual's perception of wellbeing, overall health (Galán, Meseguer, Herruzo, \& Rodríguez-Artalejo, 2010; Nakata, Takahashi, Swanson, Ikeda, \& Hojou, 2009; Powers \& Young, 2008) and quality of life (Boyle, Jones, \& Walters, 2010; Ferrer, Huedo-Medina, Johnson, Ryan, \& Pescatello, 2011; Fortier-Brochu, Beaulieu-Bonneau, Ivers, \& Morin, 2010; Ravens-Sieberer, Nickel, Erhart, \& Wille, 2006). Past studies on behavioral influences have also examined coping approaches, and investigators have shifted their focus to how personality contributes to subjective wellbeing (Diener, Suh, Lucas, \& Smith, 1999; Steel, Schmidt, \& Shultz, 2008). In this study we aim to delineate the relative contributions of individual traits of personality and health behaviors on university students' wellbeing during the emerging adulthood period.

\subsection{Health behaviors during emerging adulthood}

Early young adulthood represents a time when individuals are increasingly responsible for making decisions about their future lifestyles. This developmentally unique stage is known as emerging adulthood, and is a period of transition from adolescence to adulthood that typically takes place from the late teens to mid-twenties (Arnette, 2007; Arnette, 2010). Decisions made during this period often involve health-related choices, such as food, alcohol, tobacco, drugs, and physical activity (Larson et al., 2008; Laska, Larson, Neumark-Sztainer, \& Story, 2010; Nelson, Story, Larson, Neumark-Sztainer, \& Lytle, 2008). Many of these health behaviors affect both an individual's perceptions of wellbeing and her or his overall health. In a study of first-year Swedish university students, tobacco use correlated negatively with physical activity, self-rated physical health, and self-rated psychological health (Vaez \& Laflamme, 2003). In general, female students had healthier lifestyles and rated their quality of life higher than their male peers. Both psychological and physical self-rated health correlated strongly with self-perceived quality of life. Similarly, young adults who had experienced positive wellbeing during adolescence were more likely to report better perceived health and fewer risky health behaviors during young adulthood (Hoyt, Chase-Lansdale, McDade, \& Adam, 2012).

\subsection{Personality, health behaviors, and wellbeing}

The "Big Five" personality traits are one of the primary predictors of subjective wellbeing (McCrae \& Costa, 2008; Steel, Schmidt, \& Shultz, 2008). These five traits are: extraversion (e.g., sociability and assertiveness), neuroticism (e.g., emotional instability and impulse control), agreeableness (e.g., helpfulness and cooperativeness), conscientiousness (e.g., organization and achievement-orientation), and openness to experience (e.g., creativity and curiosity). Many of these personality traits remain fairly constant throughout an individual's life, from toddler years to young adulthood and beyond (Caspi et al., 2003; Roberts, Walton, \& Viechtbauer, 2006). A meta-analysis study found that level of neuroticism has been shown to be the best predictor of life satisfaction and happiness (DeNeve \& Cooper, 1998).

Personality is also associated with various health behaviors as they contribute in some way to decisions about lifestyle behaviors. For example, highly extraverted individuals were more likely to smoke cigarettes, consume alcohol, binge drink, and have multiple sexual partners (Raynor \& Levine, 2009). Highly conscientious individuals were more likely to wear seat belts, 
utilize alcohol-related harm reduction, exercise, get enough sleep, and consume fruits and vegetables. They were also less likely to smoke cigarettes, consume alcohol, and binge drink. Another study showed that highly conscientious individuals were less likely to engage in risky behaviors and were more likely to engage in healthy behaviors (Bogg \& Roberts, 2004).

Although the existing literature demonstrates linkages among health behaviors, personality traits, and subjective wellbeing, there is little research that simultaneously examines multiple health indicators in the context of personality and subjective wellbeing. Psychological research that focuses on personality and other individual characteristics often ignores the impact of health behaviors on wellbeing. Similarly, much of the health literature that links health behaviors with wellbeing does not consider the importance of personality traits. For example, researchers have identified correlations between dietary choices and subjective wellbeing (Smith, 2005); exercise has been linked with subjective health and wellbeing, particularly among older adults (Ransford \& Palisis, 1996); and substance abuse was found to be associated with decreased life satisfaction (Zullig, Valois, Huebner, Oeltmann, \& Drane, 2001). Yet this provides an incomplete picture of the factors that affect the wellbeing and health of emerging young adults (Bauldry, Shanahan, Boardman, Miech, \& Macmillan, 2012), and it remains unclear whether the effects of health behavior alter the personality-wellbeing relationship.

\subsection{The present study}

We address this gap in the literature by investigating the relative contributions of personality and health behaviors as predictors of subjective wellbeing among a multiethnic group of universityattending emerging young adults. Specifically, we examined the associations among two personality traits (extraversion and neuroticism), three health behaviors (substance use, physical activity, and healthy diet), and three dimensions of subjective wellbeing (positive affect, health status, and quality of life) among an ethnically diverse sample of university students. Our three overarching research questions are: (1) Are personality traits or individual health behaviors more strongly associated with subjective wellbeing? (2) Does the relationship between health behaviors and subjective wellbeing remain, after holding personality traits constant? (3) What is the relative importance and unique contribution of each individual dimension of personality traits and health behaviors on subjective wellbeing? Because health behaviors are proximal variables with more direct influence on health status, we hypothesize that health behaviors will be more strongly associated with the health dimension of subjective wellbeing than the distal variable of personality.

\section{Method}

\subsection{Participants}

Participants were drawn from a larger CDC-funded project that was approved by the first author's Institutional Review Board. Students' participation was voluntary, and informed consent was obtained prior to data collection. A total of 599 participants (169 males, 430 females) at a large public university in Southern California met the inclusion criteria for the study (i.e., they were between the ages of 18 and 25 and were characteristic of college-attending individuals during the emerging-adulthood period) (Arnette, 2010).

\subsection{Procedure}

Trained research assistants visited various general education classes on campus during the period between spring 2009 and spring 2010 to administer the survey materials. Data collection 
comprised two phases: (1) in-class paper-and-pencil survey; and (2) at-home online food survey. The first phase of the study required participants to complete the Student Health Survey (described in detail below), which consisted of basic demographics and questions on attitudes, beliefs, values, and behaviors related to the psychological, physical, and overall wellbeing of college students. Participants who successfully completed the in-class survey received a nutritious snack.

The second phase of the study required participants to complete a daily online 24-hour recall food questionnaire for a period of seven days. E-mails and text messages were sent each day to remind participants to complete the online questionnaire. A paper-and-pencil copy of the food questionnaire could be submitted when online access was not available to the participant. Participants who successfully completed the seven-day online food questionnaire received a $\$ 10$ gift card. Attrition rate between phase one (in-class paper-and-pencil survey) and phase two (athome daily online food recall) of the study was $26 \%$.

\subsection{Measures}

\subsubsection{Subjective wellbeing}

We measured three dimensions of subjective wellbeing (Galinha \& Pais-Ribeiro, 2012; Leontopoulou \& Triliva, 2012): (1) affective - positive affect; (2) physical/mental - overall health; and (3) cognitive - quality of life.

Positive affect was assessed using The Affect Balance Scale (ABS), which is a widely used self-reported measure of psychological wellbeing (Bradburn, 1969). It consists of 10 items that participants rate on their positive and negative feelings. Sample questions include "In the last month, did you feel particularly excited or interested in something?" and "In the last month, did you feel depressed or very unhappy?" Reponses ranged from $0=$ "never" to 4 = "very often." Negative-affect items were reverse scored, and then scores from all 10 items were summed to derive a total affect score, with higher values indicating more positive affect (Cronbach's $\alpha=$ $0.74)$.

Perceived overall health condition was based on respondents' self-reports to the question: "Over the past year, how would you describe your overall health compared to others your age?" Responses ranged from $1=$ "poor" to $5=$ "excellent." Self-rated health is a robust measure that is predictive of both morbidity and mortality (Bopp, Braun, Gutzwiller, \& Faeh, 2012; Eriksson, Unden, \& Elofsson, 2001).

Quality of Life Scale is a 15-item self-report questionnaire developed to assess a wide range of life domains, including physical/material wellbeing (e.g., "Being physically fit and vigorous"), personal relationships (e.g., "Close relationships with spouse or significant other", social/community involvement (e.g., "Participating in organizations and public affairs"), personal development (e.g., "Attending school, improving understanding, getting additional knowledge") and recreation (e.g., "Reading, listening to music, or observing entertainment") (Flanagan, 1978; Flanagan, 1982). Respondents were asked how satisfied they were during the past month, and responses were coded on a seven-point scale $(1=$ terrible, $2=$ unhappy, $3=$ mostly dissatisfied, $4=$ mixed, $5=$ mostly satisfied, $6=$ pleased, and $7=$ delighted). The total score was derived by summing the 15 items, with higher scores indicating better quality of life (Cronbach's $\alpha=0.85)$. 


\subsubsection{Personality}

The Student Health Survey measured two personality traits: extraversion and neuroticism (Costa \& McCrae, 1980). The scales contained a total of 16 items adopted from the Big Five Taxonomy of personality traits. Questions for the extraversion and neuroticism scales included such items as: "I see myself as someone who is talkative" and "I see myself as someone who worries a lot," respectively. Responses to these items ranged from $1=$ "disagree strongly" to 5 = "agree strongly." Total scores were derived by summing the items for each scale, with higher scores indicating stronger traits of extraversion (Cronbach's $\alpha=0.85$ ) and neuroticism (Cronbach's $\alpha=$ $0.78)$.

\subsubsection{Health behaviors}

Three domains of health behaviors served as predictors of subjective wellbeing: substance use (alcohol and cigarette use) (Leigh \& Stacy, 1993; SAMHSA, 2006), physical activity (vigorous/moderate exercise and strengthening/toning activities) (Haskell et al., 2007), and dietary intake (fruits and vegetables) (USDA, 2009). The Student Health Survey contained items to assess substance abuse and physical activity, while dietary intake was evaluated using daily online food recall.

Frequency of alcohol and tobacco use during the past 30 days was assessed with the question "Within the last 30 days, on how many days did you use alcohol (beer, wine, liquor)/cigarettes?" Responses ranged from $0=$ "never used" to $7=$ "all 30 days." Quantity of alcohol use the past 30 days was assessed with the question "The last time you 'partied'/socialized, how many alcoholic drinks did you have?" Respondent filled in a box to report the number of drinks consumed.

Questions on physical activity required participants to report vigorous/moderate aerobic activities (e.g., running, swimming, brisk walking) and strengthening/toning activities (e.g., push-ups, sit-ups, weight lifting) during the past six months. Responses ranged from $1=$ "never" to $5=$ "5-7 times per week."

Fruit and vegetable intakes based on 24-hour food recall for seven days were used as indicators of healthy eating behavior. Respondents were asked "How often did you eat fruit/vegetable today?" Responses were coded on a five-point scale ranging from $0=$ "none" to 5 $=$ "5+ times per day." Total frequency of consumption was computed for the seven days.

\subsubsection{Demographic covariates}

Demographic variables collected in the Student Health Survey included age, gender, and race, all of which have been previously associated with subjective wellbeing (Brown, Wallace, \& Williams, 2001; Diener, Suh, Lucas, \& Smith, 1999; Gutierrez, Jiminez, Hernandez, \& Puente, 2005).

\subsection{Data analysis}

Preliminary analyses consisted of examining sample characteristics with descriptive statistics, cross tabulations, independent samples t-tests, chi-squares, and bivariate correlations among the predictor and criterion variables. Hierarchical multivariate regression analyses were conducted to examine how each model contributed to the overall predictive ability and relative importance of the variables, with subjective wellbeing as the dependent variable. Demographic variables were entered as the first block, followed by personality in the second model, with the full model comprising the health behaviors. Respondents with more than three days of missing food data were excluded from the analysis. All analyses were performed using SPSS 19.0. 


\section{Results}

\subsection{Demographic characteristics of sample}

A total of 599 students met the inclusion criteria of age $18-25$ (28\% male and $72 \%$ female). The mean age was $20.85(S D=1.84)$. The racial composition of the sample was $33 \%$ White/nonHispanic, 27\% Asian/Pacific Islander, 25\% Hispanic/Latino, 12\% Multi-race/other, and 4\% Black/African American. The proportion of students reporting their health to be good, very good, or excellent was approximately $86 \%$. Gender stratified analysis showed that females scored higher on neuroticism, and males reported more frequency and quantity of alcohol intake and greater frequency of physical activity. Male students also reported better overall health than did female students (See Table 1 below).

Table 1. Sample characteristics and study variables by gender

\begin{tabular}{|c|c|c|c|c|}
\hline \multirow{2}{*}{ Variables } & \multicolumn{2}{|c|}{ Male } & \multicolumn{2}{|c|}{ Female } \\
\hline & Mean & $S D$ & Mean & $S D$ \\
\hline \multicolumn{5}{|l|}{ Demographics } \\
\hline Age & 21.11 & 1.92 & 20.75 & 1.80 \\
\hline Gender (\%) & 28.21 & & 71.79 & \\
\hline \multicolumn{5}{|l|}{ Race $(\%)^{* * *}$} \\
\hline Asian/Pacific Islander & 34.5 & & 24.3 & \\
\hline Hispanic/Latino & 21.4 & & 25.7 & \\
\hline White, non-Hispanic & 35.1 & & 31.5 & \\
\hline Black/African American & 3.0 & & 4.7 & \\
\hline Multi-race/Other & 6.0 & & 13.8 & \\
\hline \multicolumn{5}{|l|}{ Personality } \\
\hline Extraversion & 26.80 & 6.17 & 26.94 & 5.96 \\
\hline Neuroticism ${ }^{* * *}$ & 20.58 & 5.29 & 24.23 & 5.71 \\
\hline \multicolumn{5}{|l|}{ Health Behaviors } \\
\hline Alcohol-frequency ${ }^{* *}$ & 2.53 & 1.72 & 2.12 & 1.69 \\
\hline Alcohol-quantity ${ }^{* * *}$ & 4.82 & 4.07 & 2.95 & 3.18 \\
\hline Cigarette - Never used (\%) & 68.6 & & 74.4 & \\
\hline Cigarette - Have used (\%) & 31.4 & & 25.6 & \\
\hline Physical activity - Vigorous/moderate PA** & 3.74 & .93 & 3.46 & 1.04 \\
\hline Physical activity - Strength/tone PA** & 3.46 & 1.14 & 3.08 & 1.15 \\
\hline Fruit & 5.42 & 4.27 & 5.21 & 3.95 \\
\hline Vegetable & 7.72 & 4.36 & 7.53 & 3.76 \\
\hline \multicolumn{5}{|l|}{ Subjective wellbeing } \\
\hline Positive affect & 24.86 & 4.84 & 24.59 & 5.21 \\
\hline Overall health** & 3.85 & .90 & 3.52 & 1.02 \\
\hline Quality of life & 78.41 & 10.79 & 78.02 & 11.29 \\
\hline
\end{tabular}

${ }^{*} p<.05 .{ }^{* *} p<.01 .{ }^{* * *} p<.001$.

Note: Group differences tested with t-test for continuous and Chi-square for categorical variables. Male $N=169$, and female $N=430$. 
Table 2. Product-moment correlations among individual characteristics and subjective wellbeing variables

\begin{tabular}{|c|c|c|c|c|c|c|c|c|c|c|c|c|c|}
\hline Variables & 1 & 2 & 3 & 4 & 5 & 6 & 7 & 8 & 9 & 10 & 11 & 12 & 13 \\
\hline 1. Age & - & & & & & & & & & & & & \\
\hline 2. Extraversion & -.03 & - & & & & & & & & & & & \\
\hline 4. Alcohol (freq) & $.25^{* *}$ & $.18^{* *}$ & -.08 & - & & & & & & & & & \\
\hline 5. Alcohol (qty) & $.09^{*}$ & $.17^{* *}$ & $-.12^{* *}$ & $.52^{* *}$ & - & & & & & & & & \\
\hline 7. Vigorous PA & .00 & $.09^{*}$ & $-.11^{* *}$ & .03 & .02 & -.04 & - & & & & & & \\
\hline 8. Strength PA & .00 & $.12^{* *}$ & $-.12^{* *}$ & .04 & .08 & -.05 & $.62^{* *}$ & - & & & & & \\
\hline 9. Vegetable & $.11^{* *}$ & .04 & $-.11^{* *}$ & .05 & .01 & .02 & $.10^{*}$ & .06 & - & & & & \\
\hline 10. Fruit & .00 & $.09^{*}$ & $-.11^{* *}$ & -.05 & -.02 & $-.09^{*}$ & $.17^{* *}$ & $.18^{* *}$ & $.42^{* *}$ & - & & & \\
\hline 13. Quality of life & .00 & $.39^{* *}$ & $-.43^{* *}$ & -.05 & -.03 & -.02 & $.24^{* *}$ & $.23^{* *}$ & $.15^{* *}$ & $.13^{* *}$ & $.62^{* *}$ & $.26^{* *}$ & - \\
\hline
\end{tabular}

Note: Gender as a dichotomous variable and race as a categorical variable were excluded. PA = physical activity. 


\subsection{Associations between individual characteristics and subjective wellbeing}

\subsubsection{Bivariate analyses}

Pearson product-moment correlation coefficients for personality, health behaviors, and subjective wellbeing are presented in Table 2 above. Extraversion was positively associated with all substance use, health behaviors, and subjective wellbeing variables except vegetable intake. Conversely, neuroticism was negatively associated with all substance use, health behaviors, and subjective wellbeing variables except cigarette use. More alcohol use was associated with higher scores on positive affect and cigarette use was associated with lower ratings of overall health. All health behaviors of physical activity and healthy food intake were positively correlated with subjective wellbeing. Among the three dimensions of subjective wellbeing, the strongest association was between positive affect and quality of life.

\subsubsection{Multivariate analyses}

Hierarchical regression analyses were conducted to evaluate the overall strength of association and model fit when predicting subjective wellbeing using demographics (age, gender, race), personality (extraversion, neuroticism), and health behaviors (alcohol/cigarettes, vigorous/strengthening physical activity, fruit/vegetable). The overall test of model fit showed that personality and health behaviors were significantly associated with all three dimensions of subjective wellbeing after controlling for age, gender, and race (see Tables 3-5 below). Moreover, health behaviors remained predictive after holding personality constant.

Table 3. Summary of Hierarchical Regression Analysis for predicting positive affect $(n=571)$

\begin{tabular}{|c|c|c|c|c|c|c|c|c|c|}
\hline & \multicolumn{3}{|c|}{ Model 1} & \multicolumn{3}{|c|}{ Model 2} & \multicolumn{3}{|c|}{ Model 3} \\
\hline & B & SE B & $\beta$ & B & SE B & $\beta$ & B & SE B & $\beta$ \\
\hline \multicolumn{10}{|l|}{ Demographics } \\
\hline Age & 0.03 & 0.12 & 0.01 & 0.03 & 0.10 & 0.01 & 0.04 & 0.10 & 0.01 \\
\hline Gender & -0.32 & 0.48 & -0.03 & 0.97 & 0.42 & $0.09^{*}$ & 1.23 & 0.43 & $0.11^{* *}$ \\
\hline Race & 0.13 & 0.15 & 0.04 & -0.04 & 0.13 & -0.01 & -0.09 & 0.13 & -0.02 \\
\hline \multicolumn{10}{|l|}{ Personality } \\
\hline Extraversion & & & & 0.29 & 0.03 & $0.35^{* * *}$ & 0.28 & 0.03 & $0.33^{* * *}$ \\
\hline Neuroticism & & & & -0.33 & 0.03 & $-0.38^{* * *}$ & -0.32 & 0.03 & $-0.37^{* * *}$ \\
\hline \multicolumn{10}{|l|}{ Health behaviors } \\
\hline Alcohol-Frequency & & & & & & & -0.05 & 0.13 & -0.02 \\
\hline Alcohol-Quantity & & & & & & & 0.03 & 0.06 & 0.02 \\
\hline Cigarettes & & & & & & & -0.02 & 0.12 & -0.01 \\
\hline PA-Vig/mod & & & & & & & 0.18 & 0.22 & 0.04 \\
\hline PA-Streng/tone & & & & & & & 0.57 & 0.19 & $0.13^{* *}$ \\
\hline Vegetables & & & & & & & 0.00 & 0.05 & 0.00 \\
\hline Fruits & & & & & & & 0.06 & 0.05 & 0.04 \\
\hline Constant & 24.35 & 2.71 & & 22.32 & 2.54 & & 19.15 & 2.64 & \\
\hline $\mathrm{R}^{2} \Delta$ & & 0.00 & & & 0.32 & & & 0.03 & \\
\hline Adjusted $\mathrm{R}^{2}$ & & 0.00 & & & 0.32 & & & 0.33 & \\
\hline$F$ for $\Delta R^{2}$ & & 0.39 & & & $128.75^{* * *}$ & & & $3.30^{* *}$ & \\
\hline
\end{tabular}

${ }^{*} p<.05 .{ }^{* *} p<.01 .{ }^{* * *} p<.001$.

Note: $\mathrm{PA}=$ physical activity. 
Table 4. Summary of Hierarchical Regression Analysis for predicting self-rated health ( $n=$ 571)

\begin{tabular}{|c|c|c|c|c|c|c|c|c|c|}
\hline & \multicolumn{3}{|c|}{ Model 1} & \multicolumn{3}{|c|}{ Model 2} & \multicolumn{3}{|c|}{ Model 3} \\
\hline & B & SE B & $\beta$ & B & SE B & $\beta$ & B & SE B & $\beta$ \\
\hline \multicolumn{10}{|l|}{ Demographics } \\
\hline Age & -0.01 & 0.02 & -0.02 & -0.01 & 0.02 & -0.02 & -0.01 & 0.02 & -0.01 \\
\hline Gender & -0.34 & 0.09 & $-0.15^{* *}$ & -0.22 & 0.10 & $-0.10^{*}$ & -0.21 & 0.09 & $-0.09^{*}$ \\
\hline Race & -0.00 & 0.03 & -0.00 & -0.01 & 0.03 & -0.02 & -0.02 & 0.03 & -0.04 \\
\hline \multicolumn{10}{|l|}{ Personality } \\
\hline Extraversion & & & & 0.01 & 0.01 & 0.05 & 0.01 & 0.01 & 0.04 \\
\hline Neuroticism & & & & -0.03 & 0.01 & $-0.18^{* * *}$ & -0.03 & 0.01 & $-0.16^{* * *}$ \\
\hline \multicolumn{10}{|l|}{ Health behaviors } \\
\hline Alcohol- Frequency & & & & & & & -0.02 & 0.03 & 0.03 \\
\hline Alcohol-Quantity & & & & & & & -0.03 & 0.01 & -0.09 \\
\hline Cigarettes & & & & & & & -0.05 & 0.03 & -0.08 \\
\hline PA-Vig/mod & & & & & & & 0.11 & 0.05 & $0.12^{*}$ \\
\hline PA-Streng/tone & & & & & & & 0.10 & 0.04 & $0.12^{*}$ \\
\hline Vegetables & & & & & & & 0.00 & 0.01 & 0.00 \\
\hline Fruits & & & & & & & 0.03 & 0.01 & $0.12^{* *}$ \\
\hline Constant & 4.42 & 0.52 & & 4.80 & 0.58 & & 3.80 & 0.58 & \\
\hline $\mathrm{R}^{2} \Delta$ & & 0.02 & & & 0.04 & & & 0.08 & \\
\hline Adjusted $\mathrm{R}^{2}$ & & 0.02 & & & 0.05 & & & 0.13 & \\
\hline$F$ for $\Delta R^{2}$ & & $4.58^{* *}$ & & & $10.61^{* * *}$ & & & $7.65^{* * *}$ & \\
\hline
\end{tabular}

${ }^{*} p<.05 .{ }^{* *} p<.01 .{ }^{* * *} p<.001$.

Note: PA = physical activity.

Positive affect. Age, gender, and race in the initial model were not significantly related to affect (Table 3 above; $R=0.05, F(3,567)=0.39, p=0.762)$. Personality variables improved model fit significantly by accounting for $32 \%$ of the variance in the model $(R=0.56, F(2,565=128.75, p<$ $0.001)$. The addition of health behaviors in the final model increased variance accounted for to $33 \%(R=0.59, F(7,558)=3.3, p<0.01)$. Females and those who reported more strengthening/toning physical activity were associated with higher levels of positive affect (see Table 3 above). Personality traits of extraversion and neuroticism were more strongly related to positive affect than were either demographic or health-behavior variables.

Self-rated health. The initial model containing only demographic variables accounted for $2 \%$ of the variance in self-rated health (Table 4 above; $R=0.15, F(3,567)=4.58, p<0.01)$. In Model 2, personality accounted for $5 \%$ of the variance $(R=0.24, F(2,565)=10.61, p<0.001)$. When health behaviors were added, the percentage of variance accounted for increased to $13 \%(R=0.38, F(7$, $558)=7.65, p<0.001)$. Gender differences were found in all three models, with males reporting better health (see Table 4 above). No significant difference was found for extraversion, but neuroticism was negatively associated with self-rated health. Among the health behaviors, vigorous/moderate and strengthening/toning physical activities and fruit intake were significantly related to self-rated health.

Quality of Life (QoL). Age, gender, and race in the initial model were not significantly associated with quality of life (Table 5 below; $R=0.06, F(3,526)=0.58, p=0.632$ ). In Model 2, 
personality accounted for $28 \%$ of the variance in quality of life $(R=0.53, F(2,524)=100.93, p<$ 0.001). The full model including health behaviors improved model fit to $32 \%$ of the total variance $(R=0.58, F(7,517)=6.31, p<0.001)$. Gender was significantly associated with QoL, with females reporting more satisfaction than males (see Table 5 below). Extraversion was positively related to QoL, and neuroticism was negatively related to QoL. In the final model controlling for age, gender, race, and personality, vigorous/moderate and strengthening/toning physical activity were significantly associated with QoL. Frequency and quantity of alcohol consumption and vegetable intake had marginally significant relationships to QoL.

Table 5: Summary of Hierarchical Regression Analysis for predicting Quality of Life $(n=530)$

\begin{tabular}{|c|c|c|c|c|c|c|c|c|c|}
\hline & \multicolumn{3}{|c|}{ Model 1} & \multicolumn{3}{|c|}{ Model 2} & \multicolumn{3}{|c|}{ Model 3} \\
\hline & B & SE B & $\beta$ & B & SE B & $\beta$ & B & SE B & $\beta$ \\
\hline \multicolumn{10}{|l|}{ Demographics } \\
\hline Age & -0.02 & 0.26 & -0.00 & -0.05 & 0.22 & -0.01 & 0.07 & 0.23 & 0.01 \\
\hline Gender & -0.25 & 1.07 & -0.01 & 2.68 & 0.96 & $0.11^{* *}$ & 2.57 & 0.97 & $0.11^{* *}$ \\
\hline Race & 0.44 & 0.34 & 0.06 & 0.14 & 0.29 & 0.02 & 0.17 & 0.29 & 0.02 \\
\hline \multicolumn{10}{|l|}{ Personality } \\
\hline Extraversion & & & & 0.54 & 0.07 & $0.29^{* * *}$ & 0.56 & 0.07 & $0.30^{* * *}$ \\
\hline Neuroticism & & & & -0.73 & 0.08 & $-0.39^{* * *}$ & -0.69 & 0.07 & $-0.37^{* * *}$ \\
\hline \multicolumn{10}{|l|}{ Health behaviors } \\
\hline Alcohol-Frequency & & & & & & & -0.58 & 0.30 & $-0.09^{+}$ \\
\hline Alcohol-Quantity & & & & & & & -0.23 & 0.14 & $-0.07^{+}$ \\
\hline Cigarettes & & & & & & & 0.01 & 0.28 & 0.00 \\
\hline $\mathrm{PA}-\mathrm{Vig} / \mathrm{mod}$ & & & & & & & 1.15 & 0.50 & $0.11^{*}$ \\
\hline PA-Streng/tone & & & & & & & 0.89 & 0.44 & $0.09^{*}$ \\
\hline Vegetables & & & & & & & 0.20 & 0.11 & $0.07^{+}$ \\
\hline Fruits & & & & & & & 0.01 & 0.11 & 0.01 \\
\hline Constant & 77.69 & 6.04 & & 76.76 & 5.85 & & 66.20 & 5.99 & \\
\hline $\mathrm{R}^{2} \Delta$ & & 0.00 & & & 0.28 & & & 0.06 & \\
\hline Adjusted $R^{2}$ & & 0.00 & & & 0.28 & & & 0.32 & \\
\hline$F$ for $\Delta R^{2}$ & & 0.58 & & & $100.93^{* * *}$ & & & $6.31^{* * *}$ & \\
\hline
\end{tabular}

${ }^{+} p<.10{ }^{*} p<.05 .{ }^{* *} p<.01 .{ }^{* * *} p<.001$.

Note. $\mathrm{PA}=$ physical activity.

\section{Discussion}

Wellbeing is a multifaceted and multi-dimensional construct and enhancing our understanding of it during the emerging adulthood period plays an important role in the health of young people. Moreover, university-attending young adults in the United States not only think about life satisfaction and happiness frequently, they also rate them as very important, even more important than money (Diener \& Oishi, 2000). Our findings support existing literature, that personality traits are primary predictors of subjective wellbeing. In addition, we extended previous research showing that health behaviors are important contributors of subjective wellbeing beyond the effects of personality. One particular domain of health behavior, physical activity, was found to be more strongly related with subjective wellbeing than either substance 
use or dietary intake. This pattern of results was consistent across positive affect, self-rated health, and quality of life.

Consistent with previous findings, extraversion was associated with higher scores on positive affect, and neuroticism was negatively associated with positive affect. Interestingly, regular physical activity of strengthening and toning exercises was most strongly related to positive affect. Affect and personality traits demonstrated substantial variability, with positive affect more strongly associated with psychological factors than with behavioral determinants. Indeed, the literature suggests that long-term subjective wellbeing is determined by personality traits, and personality has biological components that, in turn, affect wellbeing through shared common physical underpinnings (Depue \& Collins, 1999; Schnika, Busch, \& Robichaux-Keene, 2004).

For overall health, higher scores on neuroticism were associated with lower self-rated overall health status. Vigorous and moderate physical activity, strengthening and toning physical activity, and frequency of seven-day fruit consumption were all associated with better self-rated health. This pattern of finding is generally consistent with prior research on health behaviors and self-rated health (Harrington et al., 2010; Lengyel, Tate, \& Obirek Blatz, 2009). However, our findings on the relationships between self-rated health and alcohol use and vegetable consumption did not support previous studies. Much of the previous research related to these health behaviors was conducted on middle-aged adults; different cultural influences might affect young adults' perceptions on the health effects of alcohol use and vegetable consumption. For college students who are either non-drinkers or social drinkers, alcohol might not have the same degree of impact on perceived health as for heavier drinkers. Our findings are also counter to national data showing as many as one-third of college students binge drink (American College Health Association, 2010). Despite the nonsignificant contribution of substance use and vegetable consumption, model prediction for self-rated health increased more than two-fold with the inclusion of health behaviors, further reinforcing the importance of the direct impact that health behaviors, such as physical activity, have on health outcomes.

As expected, quality of life was positively associated with extraversion and negatively associated with neuroticism. Literature has shown that personality, or individual dispositions, affect characteristic patterns of behaviors that can impact how individuals approach life and their response to circumstances (Wrosch \& Scheier, 2003). For example, extraverted individuals are more likely to approach life with optimism and goal adjustment, and dispositional optimism facilitates subjective wellbeing and overall health (Scheier, Carver, \& Bridges, 2001). In addition to the distal factor of personality, proximal factors of health behaviors were also important determinants of quality of life. Those who reported doing more vigorous/moderate and strengthening/toning physical activity reported greater satisfaction with quality of life. Physical fitness benefits both physical and psychological functioning that, in turn, influence quality of life (Berger \& Tobar, 2007). Lastly, in contrast to the findings reported by Vaez and Laflamme (2003), we did not find any association between tobacco use and quality of life. It is important to note that our study employed a multivariate approach while the Swedish study found significance only among females from bivariate correlations. Our product-moment correlations showed a weak, nonsignificant negative correlation between cigarette use and quality of life (see Table 2 above). 
Overall, across the seven health behavioral measures, physical activity contributed the most power to predict subjective wellbeing. Vigorous/moderate exercise appeared to be an important predictor among the three domains of health behaviors, when controlling for age, gender, race, and personality. This supports existing literature linking physical activity with greater life satisfaction, positive affect, and happiness (Hyde, Maher, \& Elavsky, 2013). Consistent with prior literature, our analyses indicated that personality traits were highly associated with subjective wellbeing. Both extraversion and neuroticism were moderately correlated with positive affect and quality of life, suggesting these two dimensions of subjective wellbeing are impacted more by individual perceptions, traits, and cognitive dispositions. In comparison, the weaker relationship between personality traits and overall health supports our hypothesis that behavioral variables are also important predictors of health-related subjective wellbeing. When health behaviors were added to the model, they increased the total variance accounted for in overall health more than two-fold.

\subsection{Limitations}

There are several limitations with this study that may impact the interpretation of our findings. First, our sample consisted of only college students between the ages of 18 and 25 and thus may not generalize to older students or non-college students. We purposely limited our sample to this age group because emerging adulthood is a developmentally unique and important stage that is qualitatively different from adolescence and young adulthood (Nelson et al., 2008). Thus, this limitation is also a strength of our study because many studies combine all college students in one group regardless of age or consider only certain class standings (e.g., freshmen). Second, causal inferences cannot be made, as the results are based on cross-sectional data. While our multivariate approach using hierarchical regression analyses afforded us the ability to make predictions while controlling for the effects of various covariates, it is possible that high subjective wellbeing influences substance use and health behaviors. It is also possible that personality and health behaviors both acted in a synergistic manner on subjective wellbeing. We tested for possible effects of personality $x$ health behavior interactions, and the results were not significant. Third, self-reports are susceptible to reporting bias, possibly affected by social desirability or misreporting of alcohol and tobacco use. In addition, using online surveys to collect daily food intake recall may also pose potential reporting issues, including response bias and authenticity of the person answering the questions. We attempted to reduce bias by ensuring confidentiality during data collection and in food recall with a 30-minute orientation and training with participants on how to estimate portion size using the images provided in the survey; we also sent text reminders and provided a hardcopy survey as backup. Lastly, while an investigation of all aspects of personality would be ideal, our study evaluated only two of the Big Five personality traits within the limitations of the available measures, thus limiting our ability to interpret how other facets of personality traits correlate with health behaviors and subjective wellbeing. However, the significant results we found relating to extraversion and neuroticism along with behavioral determinants to wellbeing can build a foundation for the investigation of the other personality traits. 


\subsection{Conclusions}

Notwithstanding its limitations, this study extends prior research and highlights the importance of maintaining a healthy lifestyle during the emerging adulthood period. This period of transition marks the beginning of many newly adapted health behaviors that can lead to increased health risks. Our study is novel in several aspects. To our knowledge, this is the first study to examine personality and health behavior variables simultaneously as predictors of subjective wellbeing among a group of racially/ethnically diverse university-attending young adults. We demonstrated that certain health behaviors are associated with wellbeing beyond the effects of personality traits. Including substance use, physical activity, and dietary intake as predictors provided a multidimensional pattern of lifestyle behaviors that contribute to college students' wellbeing and have lifelong health implications. Rather than using a single, global measure, we assessed subjective wellbeing from three major dimensions (affective, physical/psychological, and cognitive appraisal), providing a more comprehensive understanding of the contributions of personality and health behaviors on each unique, but related, area of wellbeing. Lastly, our study contributes to the growing body of literature on health promotion and positive psychology that is in line with the emphases of Healthy People 2020 and Healthy Campus 2020 - studying healthrelated quality of life and wellbeing. Future research could examine other personality traits (e.g., conscientiousness, sensation-seeking) and health behaviors (e.g., sleep quality, sexual behaviors) and their potential interactions with wellbeing. Conscientious individuals, for example, have been shown to exhibit more health-related and fewer risk-related health behaviors.

By better understanding the factors that influence the wellbeing of emerging young adults, we will be able to tailor health and wellness programs to improve quality of life in this age group, potentially impacting lifestyle choices and overall health. For example, health programs can adopt a more holistic and interdisciplinary approach by incorporating positive psychology and public health intervention strategies to identify individual characteristics and assess lifestyle health behaviors, particularly physical activity, to promote wellbeing among young adults. Health-related decisions made in college during young adulthood can affect lifelong health; college health programs that are designed to address both physical and personality-based factors could help lead to healthier - and happier - adults.

\section{Acknowledgments}

This research was supported by the Center for the Promotion of Healthy Lifestyles and Obesity Prevention at California State University, Fullerton and funded by CDC, National Center for Chronic Disease Prevention and Health Promotion, the Division of Nutrition, Physical Activity, and Obesity (Grant \#5H75DP001814-02), an award to the first and second authors.

\section{Authors}

Chia-Hsin Emily Cheng

California State University, Fullerton

echeng@fullerton.edu

Jie W Weiss

California State University, Fullerton 
Judith M Siegel

University of California, Los Angeles

\section{Publishing Timeline}

Received 22 July 2014

Accepted 22 May 2015

Published 30 July 2015

\section{References}

American College Health Association. (2010). National College Health Assessment-II Reference Group Executive Summary Fall 2009. Baltimore: American College Health Association.

American College Health Association. (2012, June) Healthy Campus 2020. http://www.acha.org/healthycampus/.

Arnette, J. J. (2007). Emerging adulthood: What is it, and what is it good for? Journal Compilation, Society for Research in Child Development, 1, 68-73.

Arnette, J. J. (2010). Emerging adulthood: A theory of development from the late teens through the twenties. American Psychologist, 55(5), 469-480. http://dx.doi.org/10.1037/0003-066X.55.5.469

Bauldry, S., Shanahan, M. J., Boardman, J. D., Miech, R. A., \& Macmillan, R. (2012). A life course model of self-rated health through adolescence and young adulthood. Social Science $\mathcal{E}$ Medicine, 75, 1311-1320. http://dx.doi.org/10.1016/j.socscimed.2012.05.017

Berger, B. G., \& Tobar, D. A. (2007). Physical activity and quality of life: Key considerations. In G. Tenenbaum \& R. Eklund (Eds.), Handbook of sports psychology, 598-620, Hoboken, NJ: John Wiley \& Sons, Inc.

Bogg, T., \& Roberts, B. W. (2004). Conscientiousness and health-related behaviors: A meta-analysis of the leading behavioral contributors to mortality. Psychological Bulletin, 130(6), 887-919. http://dx.doi.org/10.1037/0033-2909.130.6.887

Bopp, M., Braun, J., Gutzwiller, F., \& Faeh, D. (2012). Health risk or resource? Gradual and independent association between self-rated health and mortality persists over 30 years. PLoS ONE, 7, 1-10. http://dx.doi.org/10.1371/journal.pone.0030795

Boyle, S. E., Jones, G. L., \& Walters, S. J. (2010). Physical activity, quality of life, weight status and diet in adolescents. Quality of Life Research: An International Journal of Quality of Life Aspects of Treatment, Care E Rehabilitation, 19(7), 943-954. http://dx.doi.org/10.1007/s11136-010-9659-8

Bradburn, N. M. (1969). The structure of psychological wellbeing. Chicago: Aldine Publishing.

Brown, T. N., Wallace, J. M., \& Williams, D. R. (2001). Race-related correlates of young adults' subjective wellbeing. Social Indicators Research, 53, 97-116. http://dx.doi.org/10.1023/A:1007190226538

Caspi, A., Harrington, H., Milne, B., Amell, J. W., Theodore, R. F., \& Moffitt, T. E. (2003). Children's behavioral styles at age 3 are linked to their adult personality traits at age 26. Journal of Personality, 71(4), 495-514. http://dx.doi.org/10.1111/1467-6494.7104001

Centers for Disease Control and Prevention [CDC]. (2009). Summary health statistics for U.S. adults: National health interview survey. Vital Health Stat, 10, 249.

Costa, P. T., \& McCrae, R. R. (1980). Influence of extraversion and neuroticism on subjective wellbeing: Happy and unhappy people. Journal of Personality and Social Psychology, 38, 668-678. http://dx.doi.org/10.1037/0022-3514.38.4.668

DeNeve, K., \& Cooper, H. (1998). The happy personality: A meta-analysis of 137 personality traits and subjective wellbeing. Psychological Bulletin, 124(2), 197-229. http://dx.doi.org/10.1037/0033$\underline{2909.124 .2 .197}$ 
Depue, R. A., \& Collins, P. F. (1999). Neurobiology of the structure of personality: Dopamine, facilitation of incentive motivation, and extraversion. Behavioral and Brain Sciences, 22, 491-569. http://dx.doi.org/10.1017/S0140525X99002046

Diener, E. (2000). Subjective wellbeing: The science of happiness and a proposal for a national index. American Psychologist, 55, 34-43. http://dx.doi.org/10.1037/0003-066X.55.1.34

Diener, E., \& Oishi, S. (2000). Money and happiness: Income and subjective well-being across nations. In E. Diener \& E. M. Suh (Eds.), Culture and subjective well-being (pp. 185-218). Cambridge, MA: The MIT Press.

Diener, E., \& Seligman, M. E. (2004). Beyond money: Toward an economy of wellbeing. Psychological Science in the Public Interest, 5(1), 1-31. http://dx.doi.org/10.1111/j.0963-7214.2004.00501001.x

Diener, E., Suh, E. M., Lucas, R. E., \& Smith, H. L. (1999). Subjective wellbeing: Three decades of progress. Psychological Bulletin, 125, 276-302. http://dx.doi.org/10.1037/0033-2909.125.2.276

Dunn, H. L. (1973). High level wellness. Arlington: R.W. Beatty, Ltd.

Eriksson, I., Unden, A. L., \& Elofsson, S. (2001). Self-rated health. Comparisons between three different measures. Results from a population study. International Journal of Epidemiology, 30, 326-333. http://dx.doi.org/10.1093/ije/30.2.326

Ferrer, R. A., Huedo-Medina, T. B., Johnson, B. T., Ryan, S., \& Pescatello, L. S. (2011). Exercise interventions for cancer survivors: A meta-analysis of quality of life outcomes. Annals of Behavioral Medicine, 41(1), 32-47. http://dx.doi.org/10.1007/s12160-010-9225-1

Flanagan, J. C. (1978). A research approach to improving our quality of life. American Psychologist, 33, 138147. http://dx.doi.org/10.1037/0003-066X.33.2.138

Flanagan, J. C. (1982). Measurement of quality of life: current state of the art. Archives of Physical Medicine $\mathcal{E}$ Rehabilitation, 63, 56-59.

Fortier-Brochu, É., Beaulieu-Bonneau, S., Ivers, H., \& Morin, C. M. (2010). Relations between sleep, fatigue, and health-related quality of life in individuals with insomnia. Journal of Psychosomatic Research, 69(5), 475-483. http://dx.doi.org/10.1016/j.jpsychores.2010.05.005

Galán, I., Meseguer, C. M., Herruzo, R., \& Rodríguez-Artalejo, F. (2010). Self-rated health according to amount, intensity and duration of leisure time physical activity. Preventive Medicine, 51(5), 378-383. http://dx.doi.org/10.1016/j.ypmed.2010.09.001

Galinha, I., \& Pais-Ribeiro, J. L. (2012). Cognitive, affective and contextual predictors of subjective wellbeing. International Journal of Wellbeing, 2(1), 34-53. http://dx.doi.org/10.5502/ijw.v2i1.3

Gutierrez, J. L. G., Jiminez, B. M., Hernandez, E. G., \& Puente, C. P. (2005). Personality and subjective wellbeing: Big five correlates and demographic variables. Personality and Individual Differences, 38, 1561-1569. http://dx.doi.org/10.1016/j.paid.2004.09.015

Harrington, J., Perry, I. J., Lutomski, J., Fitzgerald, A. P., Sheily, F., McGee, H., .. \& Shelley, E. (2010). Living longer and feeling better: Healthy lifestyle, self-rated health, obesity and depression in Ireland. European Journal of Public Health, 20, 91-95. http://dx.doi.org/10.1093/eurpub/ckp102

Haskell, W. L., Lee, I. M., Pate, R. P., Powell, K. E., Blair, S. N, Barry, A., ... \& Bauman, A. (2007). Physical activity and public health: Updated recommendation for adults from the American College of Sports Medicine and the American Heart Association. Circulation, 116(9), 1081-1093. http://dx.doi.org/10.1161/CIRCULATIONAHA.107.185649

Hoyt, L. T., Chase-Lansdale, L., McDade, T. W., \& Adam, E. K. (2012). Positive youth, healthy adults: Does positive wellbeing in adolescence predict better perceived health and fewer risky health behaviors in young adulthood? Journal of Adolescent Health, 50, 66-73. http://dx.doi.org/10.1016/j.jadohealth.2011.05.002

Hyde, A. L., Maher, J. P., \& Elavsky, S. (2013). Enhancing our understanding of physical activity and wellbeing with a lifespan perspective. International Journal of Wellbeing, 3(1), 98-115. http://dx.doi.org/10.5502/ijw.v3i1.6 
Larson, N. I., Neumark-Sztainer, D. R., Harnack, L. J., Wall, M. M., Story, M. T., \& Eisenberg, M. E. (2008). Fruit and vegetable intake correlates during the transition to young adulthood. American Journal of Preventive Medicine, 35(1), 33-37. http://dx.doi.org/10.1016/j.amepre.2008.03.019

Laska, M. N., Larson, N. I., Neumark-Sztainer, D., \& Story, M. (2010). Dietary patterns and home food availability during emerging adulthood: do they differ by living situation? Public Health Nutrition, 13(2), 222-228. http://dx.doi.org/10.1017/S1368980009990760

Leigh, B. C., \& Stacy, A. W. (1993). Alcohol outcome expectancies: Scale construction and predictive utility in higher order confirmatory models. Psychological Assessment, 5, 216-229. http://dx.doi.org/10.1037/1040-3590.5.2.216

Lengyel, C. O., Tate, R. B., \& Obirek Blatz, A. K. (2009). The relationship between food group consumption, self-rated health, and life satisfaction of community-dwelling Canadian older men: The Manitoba follow-up study. Journal of Nutrition for Elderly, 28, 158-173. http://dx.doi.org/10.1080/01639360902950182

Leontopoulou, S., \& Triliva, S. (2012). Explorations of subjective wellbeing and character strengths among a Greek University student sample. International Journal of Wellbeing, 2(3), 251-270. http://dx.doi.org/10.5502/ijw.v2.i3.6

McCrae, R. R., \& Costa, P. T. (2008). Empirical and theoretical status of the Five-Factor Model of personality traits. In G. J. Boyle, G. Matthews, \& D. H. Sakloske (Eds.), Personality theory and assessment: Personality theories and model (pp. 273-294). London: Sage. http://dx.doi.org/10.4135/9781849200462.n13

Nakata, A., Takahashi, M., Swanson, N. G., Ikeda, T., \& Hojou, M. (2009). Active cigarette smoking, secondhand smoke exposure at work and home, and self-rated health. Public Health, 123(10), 650-656. http://dx.doi.org/10.1016/j.puhe.2009.09.006

Nelson, M. C., Story, M., Larson, N. I., Neumark-Sztainer, D., \& Lytle, L. A. (2008). Emerging adulthood and college-aged youth: An overlooked age for weight-related behavior change. Obesity, 16, 22052211. http://dx.doi.org/10.1038/oby.2008.365

Powers, J. R., \& Young, A. F. (2008). Longitudinal analysis of alcohol consumption and health of middleaged women in Australia. Addiction, 103(3), 424-432. http://dx.doi.org/10.1111/j.1360$\underline{0443.2007 .02101 . x}$

Pressman, S. D., \& Cohen, S. (2005). Does positive affect influence health? Psychological Bulletin, 131, 925971. http://dx.doi.org/10.1037/0033-2909.131.6.925

Ransford, H. E., \& Palisis, B. J. (1996). Aerobic exercise, subjective health and psychological wellbeing within age and gender subgroups. Social Science \& Medicine, 42(11), 1555-1559. http://dx.doi.org/10.1016/0277-9536(95)00252-9

Ravens-Sieberer, U., Nickel, J., Erhart, M., \& Wille, N. (2006). Risk behaviour and health-related quality of life among European adolescents. Sucht: Zeitschrift für Wissenschaft und Praxis, 52(4), 236-244. http://dx.doi.org/10.1024/2006.04.03

Raynor, D., \& Levine, H. (2009). Associations between the five-factor model of personality and health behaviors among college students. Journal of American College Health, 58(1), 73-82. http://dx.doi.org/10.3200//ACH.58.1.73-82

Roberts, B. W., Walton, K. E., \& Viechtbauer, W. (2006). Patterns of mean-level change in personality traits across the life course: A meta-analysis of longitudinal studies. Psychological Bulletin, 132(1), 1-25. http://dx.doi.org/10.1037/0033-2909.132.1.1

Scheier, M. F., Carver, C. S., \& Bridges, M. W. (2001). Optimism, pessimism, and psychological wellbeing. In: E. C. Chang (Ed.), Optimism and pessimism (pp. 189-216). Washington: American Psychological Association. 
Schnika, J. A., Busch, R. M., \& Robichaux-Keene, N. (2004). A meta-analysis of the association between serotonin transporter gene polymorphism (5-HTTLPR) and trait anxiety. Molecular Psychiatry, 9, 197202. http://dx.doi.org/10.1038/sj.mp.4001405

Smith, A. P. (2005). The concept of wellbeing: Relevance to nutrition research. British Journal of Nutrition, 95, S1-S5. http://dx.doi.org/10.1079/BJN20041351

Steel, P., Schmidt, J., \& Shultz, J. (2008) Refining the relationship between personality and subjective wellbeing. Psychological Bulletin, 134, 138-161. http://dx.doi.org/10.1037/0033-2909.134.1.138

Substance Abuse and Mental Health Services Administration [SAMHSA]. (2006). Results from the 2005 National Survey on Drug Use and Health: National Findings. NSDUH Series H-30, DHHS Pub No. SMA 06-4194. Rockville, MD: SAMHSA, Office of Applied Studies.

U.S. Census (2011, June). Facts for features. http://www.census.gov/newsroom/releases/archives/facts for features special editions/cb11$\underline{\text { ff15.html }}$

U.S. Department of Agriculture [USDA] (2009). Dietary guidelines for Americans 2005. http://www.health.gov/dietaryguidelines/dga2005/document/

U.S. Department of Health and Human Services [USDHHS]. (2010). Healthy People 2020. Washington, D.C.: Government Publications.

Vaez, M., \& Laflamme, L. (2003) Health behaviors, self-rated health, and quality of life: A study among first-year Swedish university students. Journal of American College Health, 51(4), 156-162. http://dx.doi.org/10.1080/07448480309596344

Wrosch, C., \& Scheier, M. F. (2003). Personality and quality of life: The importance of optimism and goal adjustment. Quality of Life Research, 12, 59-72. http://dx.doi.org/10.1023/A:1023529606137

Zullig, K. J., Valois, R. F., Huebner, E. S., Oeltmann, J. E., \& Drane, J. W. (2001). Relationship between perceived life satisfaction and adolescents' substance abuse. Journal of Adolescent Health, 29, 279-288. http://dx.doi.org/10.1016/S1054-139X(01)00269-5 


\section{Appendix: Affect Balance Scale}

Below is a list of the ways you might have FELT or BEHAVED. Please indicate how often you felt this way during the past month (check one).

\begin{tabular}{|c|c|c|c|c|c|c|}
\hline \multicolumn{2}{|c|}{ In the last month did you feel... } & $\begin{array}{c}\text { Never } \\
0\end{array}$ & $\begin{array}{c}\text { Almost Never } \\
1\end{array}$ & $\begin{array}{c}\text { Sometimes } \\
2\end{array}$ & $\begin{array}{c}\text { Fairly Often } \\
3\end{array}$ & $\begin{array}{c}\text { Very Often } \\
4\end{array}$ \\
\hline I1 & $\begin{array}{l}\text { particularly excited or } \\
\text { interested in something? }\end{array}$ & $\square_{0}$ & $\square_{1}$ & $\square_{2}$ & $\square_{3}$ & $\square_{4}$ \\
\hline$I 2$ & $\begin{array}{l}\text { proud because someone } \\
\text { complimented you on } \\
\text { something you had done? }\end{array}$ & $\square_{0}$ & $\square_{1}$ & $\square_{2}$ & $\square_{3}$ & $\square_{4}$ \\
\hline I3 & $\begin{array}{l}\text { pleased about having } \\
\text { accomplished something? }\end{array}$ & $\square_{0}$ & $\square_{1}$ & $\square_{2}$ & $\square_{3}$ & $\square_{4}$ \\
\hline$I 4$ & on top of the world? & $\square_{0}$ & $\square_{1}$ & $\square_{2}$ & $\square_{3}$ & $\square_{4}$ \\
\hline I5 & $\begin{array}{l}\text { that things were going your } \\
\text { way? }\end{array}$ & $\square_{0}$ & $\square_{1}$ & $\square_{2}$ & $\square_{3}$ & $\square_{4}$ \\
\hline I6 & $\begin{array}{l}\text { so restless that you couldn't sit } \\
\text { long in a chair? }\end{array}$ & $\square_{0}$ & $\square_{1}$ & $\square_{2}$ & $\square_{3}$ & $\square_{4}$ \\
\hline I7 & $\begin{array}{l}\text { very lonely or remote from } \\
\text { other people? }\end{array}$ & $\square_{0}$ & $\square_{1}$ & $\square_{2}$ & $\square_{3}$ & $\square_{4}$ \\
\hline I8 & bored? & $\square_{0}$ & $\square_{1}$ & $\square_{2}$ & $\square_{3}$ & $\square_{4}$ \\
\hline 19 & depressed or very unhappy? & $\square_{0}$ & $\square_{1}$ & $\square_{2}$ & $\square_{3}$ & $\square_{4}$ \\
\hline I10 & $\begin{array}{l}\text { upset because someone } \\
\text { criticized you? }\end{array}$ & $\square_{0}$ & $\square_{1}$ & $\square_{2}$ & $\square_{3}$ & $\square_{4}$ \\
\hline
\end{tabular}

\section{Overall health}

F2. Over the past year, how would you describe your overall health compared to others your age?
$\square_{5}$ Excellent
$\square_{4}$ Very Good
$\square_{3}$ Good
$\square_{2}$ Fair
$\square_{1}$ Poor 


\section{Quality of Life}

Please read each item and check the box that best describes how SATISFIED you are at this time. Please answer each item even if you do not currently participate in an activity or have a relationship. You can be satisfied or dissatisfied with not doing the activity or having the relationship. Please indicate how often you felt this way during the past month (check one).

\begin{tabular}{|c|c|c|c|c|c|c|c|c|}
\hline & & $\begin{array}{c}\text { Delighted } \\
7\end{array}$ & $\begin{array}{c}\text { Pleased } \\
6\end{array}$ & $\begin{array}{c}\text { Mostly } \\
\text { Satisfied } \\
5 \\
\end{array}$ & $\begin{array}{c}\text { Mixed } \\
4\end{array}$ & $\begin{array}{c}\text { Mostly } \\
\text { Dissatisfied } \\
3 \\
\end{array}$ & $\begin{array}{c}\text { Unhappy } \\
2\end{array}$ & $\begin{array}{c}\text { Terrible } \\
1\end{array}$ \\
\hline$J 1$ & $\begin{array}{l}\text { Material comforts - home, } \\
\text { food, conveniences, financial } \\
\text { security }\end{array}$ & $\square_{7}$ & $\square_{6}$ & $\square_{5}$ & $\square_{4}$ & $\square_{3}$ & $\square_{2}$ & $\square_{1}$ \\
\hline$J 2$ & $\begin{array}{l}\text { Health-being physically fit } \\
\text { and vigorous }\end{array}$ & $\square_{7}$ & $\square_{6}$ & $\square_{5}$ & $\square_{4}$ & $\square_{3}$ & $\square_{2}$ & $\square_{1}$ \\
\hline$J 3$ & $\begin{array}{l}\text { Relationships with parents, } \\
\text { siblings, \& other relatives } \\
\text { (communicating, visiting, } \\
\text { helping) }\end{array}$ & $\square_{7}$ & $\square_{6}$ & $\square_{5}$ & $\square_{4}$ & $\square_{3}$ & $\square_{2}$ & $\square_{1}$ \\
\hline$J 4$ & Having and rearing children & $\square_{7}$ & $\square_{6}$ & $\square_{5}$ & $\square_{4}$ & $\square_{3}$ & $\square_{2}$ & $\square_{1}$ \\
\hline$J 5$ & $\begin{array}{l}\text { Close relationships with } \\
\text { spouse or significant other }\end{array}$ & $\square_{7}$ & $\square_{6}$ & $\square_{5}$ & $\square_{4}$ & $\square_{3}$ & $\square_{2}$ & $\square_{1}$ \\
\hline J6 & Close friends & $\square_{7}$ & $\square_{6}$ & $\square_{5}$ & $\square_{4}$ & $\square_{3}$ & $\square_{2}$ & $\square_{1}$ \\
\hline$J 7$ & $\begin{array}{l}\text { Helping and encouraging } \\
\text { others, volunteering, giving } \\
\text { advice }\end{array}$ & $\square_{7}$ & $\square_{6}$ & $\square_{5}$ & $\square_{4}$ & $\square_{3}$ & $\square_{2}$ & $\square_{1}$ \\
\hline$J 8$ & $\begin{array}{l}\text { Participating in organizations } \\
\text { and public affairs }\end{array}$ & $\square_{7}$ & $\square_{6}$ & $\square_{5}$ & $\square_{4}$ & $\square_{3}$ & $\square_{2}$ & $\square_{1}$ \\
\hline$J 9$ & $\begin{array}{l}\text { Learning - attending school, } \\
\text { improving understanding, } \\
\text { getting additional knowledge }\end{array}$ & $\square_{7}$ & $\square_{6}$ & $\square_{5}$ & $\square_{4}$ & $\square_{3}$ & $\square_{2}$ & $\square_{1}$ \\
\hline$J 10$ & $\begin{array}{l}\text { Understanding yourself- } \\
\text { knowing your assets and } \\
\text { limitations - knowing what } \\
\text { life is about }\end{array}$ & $\square_{7}$ & $\square_{6}$ & $\square_{5}$ & $\square_{4}$ & $\square_{3}$ & $\square_{2}$ & $\square_{1}$ \\
\hline$J 11$ & Work-job or in home & $\square_{7}$ & $\square_{6}$ & $\square_{5}$ & $\square_{4}$ & $\square_{3}$ & $\square_{2}$ & $\square_{1}$ \\
\hline$J 12$ & Expressing yourself creatively & $\square_{7}$ & $\square_{6}$ & $\square_{5}$ & $\square_{4}$ & $\square_{3}$ & $\square_{2}$ & $\square_{1}$ \\
\hline$J 13$ & $\begin{array}{l}\text { Socializing - meeting other } \\
\text { people, doing things, parties, } \\
\text { etc. }\end{array}$ & $\square_{7}$ & $\square_{6}$ & $\square_{5}$ & $\square_{4}$ & $\square_{3}$ & $\square_{2}$ & $\square_{1}$ \\
\hline$J 14$ & $\begin{array}{l}\text { Reading, listening to music, or } \\
\text { observing entertainment }\end{array}$ & $\square_{7}$ & $\square_{6}$ & $\square_{5}$ & $\square_{4}$ & $\square_{3}$ & $\square_{2}$ & $\square_{1}$ \\
\hline$J 15$ & $\begin{array}{l}\text { Participating in active } \\
\text { recreation }\end{array}$ & $\square_{7}$ & $\square_{6}$ & $\square_{5}$ & $\square_{4}$ & $\square_{3}$ & $\square_{2}$ & $\square_{1}$ \\
\hline
\end{tabular}




\section{Personality}

Here are a number of CHARACTERISTICS that may or may not apply to you. Please indicate the extent to which you agree or disagree with each of the following statements (check one).

\begin{tabular}{|c|c|c|c|c|c|c|}
\hline \multicolumn{2}{|c|}{ I see myself as someone who... } & \multirow{2}{*}{$\begin{array}{c}\begin{array}{c}\text { Disagree } \\
\text { strongly } \\
\mathbf{1}\end{array} \\
\square_{1}\end{array}$} & \multirow{2}{*}{$\begin{array}{c}\begin{array}{c}\text { Disagree a } \\
\text { little } \\
2\end{array} \\
\square_{2}\end{array}$} & \multirow{2}{*}{$\begin{array}{c}\text { Neither agree } \\
\text { nor disagree } \\
3 \\
\square_{3}\end{array}$} & \multirow{2}{*}{$\begin{array}{c}\begin{array}{c}\text { Agree a } \\
\text { little } \\
4\end{array} \\
\square_{4}\end{array}$} & \multirow{2}{*}{$\begin{array}{c}\begin{array}{c}\text { Agree } \\
\text { strongly } \\
5\end{array} \\
\square_{5}\end{array}$} \\
\hline N1 & is talkative. & & & & & \\
\hline N2 & is depressed, blue. & $\square_{1}$ & $\square_{2}$ & $\square_{3}$ & $\square_{4}$ & $\square_{5}$ \\
\hline N3 & is reserved. & $a_{1}$ & $a_{2}$ & $\square_{3}$ & $\square_{4}$ & $\square_{5}$ \\
\hline N4 & $\begin{array}{l}\text { is relaxed, handles stress } \\
\text { well. }\end{array}$ & $\square_{1}$ & $\square_{2}$ & $\square_{3}$ & $\square_{4}$ & $\square_{5}$ \\
\hline N5 & is full of energy. & $\square_{1}$ & $\square_{2}$ & $\square_{3}$ & $\square_{4}$ & $\square_{5}$ \\
\hline N6 & can be tense. & $a_{1}$ & $\square_{2}$ & $\square_{3}$ & $\square_{4}$ & $\square_{5}$ \\
\hline N7 & $\begin{array}{l}\text { generates a lot of } \\
\text { enthusiasm. }\end{array}$ & $\square_{1}$ & $\square_{2}$ & $\square_{3}$ & $\square_{4}$ & $\square_{5}$ \\
\hline N8 & worries a lot. & $a_{1}$ & $\square_{2}$ & $\square_{3}$ & $\square_{4}$ & $\square_{5}$ \\
\hline N9 & tends to be quiet. & $a_{1}$ & $\square_{2}$ & $\square_{3}$ & $\square_{4}$ & $\square_{5}$ \\
\hline N10 & $\begin{array}{l}\text { is emotionally stable, } \\
\text { not easily upset. }\end{array}$ & $a_{1}$ & $\square_{2}$ & $\square_{3}$ & $\square_{4}$ & $\square_{5}$ \\
\hline N11 & $\begin{array}{l}\text { has an assertive } \\
\text { personality. }\end{array}$ & $a_{1}$ & $\square_{2}$ & $\square_{3}$ & $\square_{4}$ & $\square_{5}$ \\
\hline N12 & can be moody. & $a_{1}$ & $\square_{2}$ & $\square_{3}$ & $\square_{4}$ & $\square_{5}$ \\
\hline N13 & $\begin{array}{l}\text { is sometimes shy, } \\
\text { inhibited. }\end{array}$ & $a_{1}$ & $\square_{2}$ & $\square_{3}$ & $\square_{4}$ & $\square_{5}$ \\
\hline N14 & $\begin{array}{l}\text { remains calm in tense } \\
\text { situations. }\end{array}$ & $\square_{1}$ & $\square_{2}$ & $\square_{3}$ & $\square_{4}$ & $\square_{5}$ \\
\hline N15 & is outgoing, sociable. & $\square_{1}$ & $\square_{2}$ & $\square_{3}$ & $\square_{4}$ & $\square_{5}$ \\
\hline N16 & gets nervous easily. & $a_{1}$ & $\square_{2}$ & $\square_{3}$ & $\square_{4}$ & $\square_{5}$ \\
\hline
\end{tabular}




\section{Alcohol and Tobacco}

Within the last 30 days, on how many days did you use: (Mark one for each row)

\begin{tabular}{|c|c|c|c|c|c|c|c|c|c|}
\hline & & $\begin{array}{c}\text { Never } \\
\text { Used }\end{array}$ & $\begin{array}{c}\text { Have } \\
\text { Used } \\
\text { But Not } \\
\text { In Last } \\
\text { 30 Days }\end{array}$ & $\begin{array}{l}1-2 \\
\text { Days }\end{array}$ & $\begin{array}{l}3-5 \\
\text { Days }\end{array}$ & $\begin{array}{c}\text { 6-9 } \\
\text { Days }\end{array}$ & $\begin{array}{l}10-19 \\
\text { Days }\end{array}$ & $\begin{array}{l}20-29 \\
\text { Days }\end{array}$ & $\begin{array}{l}\text { All } 30 \\
\text { Days }\end{array}$ \\
\hline C1 & Cigarettes & $\square_{0}$ & $\square_{1}$ & $\square_{2}$ & $\square_{3}$ & $\square_{4}$ & $\square_{5}$ & $\square_{6}$ & $\square_{7}$ \\
\hline C3 & $\begin{array}{l}\text { Alcohol } \\
\text { (beer, } \\
\text { wine, } \\
\text { liquor) }\end{array}$ & $\square_{0}$ & $\boldsymbol{a}_{1}$ & $\square_{2}$ & $\square_{3}$ & $\square_{4}$ & $\square_{5}$ & $\square_{6}$ & $\square_{7}$ \\
\hline
\end{tabular}

C8. The last time you "partied"/socialized, how many alcoholic drinks did you have? One drink is equal to one $12 \mathrm{oz}$. beer, one $4-5 \mathrm{oz}$. glass of wine, or one shot of distilled liquor. State your best estimate.

\begin{tabular}{|l|}
\hline $\begin{array}{l}\text { Number of } \\
\text { Drinks }\end{array}$ \\
\hline \\
\hline
\end{tabular}

\section{Physical Activity}

F12. Considering your participation in vigorous/moderate exercise, such as running and swimming, or moderate exercise such as brisk walking, how often have you engaged in these activities over the past six months?

$\square_{1}$ Never

$\square_{2}$ Rarely: a few times per month

$\square_{3}$ Sometimes: about once per week

$\square_{4}$ Often: usually $2-4$ times per week

$\square_{5}$ Very often: $5-7$ times per week

F14. Considering your participation in exercise to strengthen or tone your muscles, such as pushups, sit-ups, or weight lifting, how often have you engaged in these activities over the past six months?

$\square_{1}$ Never

$\square_{2}$ Rarely: a few times per month

$\square_{3}$ Sometimes: about once per week

$\square_{4}$ Often: usually $2-4$ times per week

$\square_{5}$ Very often: $5-7$ times per week 


\section{Vegetables and Fruit Intake}

\section{Food Item Taken - Vegetables}

5. Vegetables (broccoli, onion, celery, lettuce, etc.) HOW OFTEN did you eat these items TODAY?
None
1 time per day
$\bigcirc_{\text {day }} 2$ times per
$\bigcirc_{\text {day }} 3$ times per
$\bigcirc_{\text {day }} 4$ times per
$\bigcirc_{\text {day }} 5+$ times per

\section{Food Item Taken - Fruits}

8. Fruits (apple, melon, pear, kiwi, etc.)

HOW OFTEN did you eat these items TODAY?

$\bigcirc$ None

1 time per day

$\bigcirc_{\text {day }} 2$ times per

$\bigcirc_{\text {day }} 3$ times per

$\bigcirc_{\text {day }} 4$ times per

$\bigcirc_{\text {day }} 5+$ times per

\section{Demographics}

A1. What is your age? years

A2. Your gender

$\square_{1}$ Male

$\square_{2}$ Female

A3. What is your race/ethnicity (check one)?

$\square_{1}$ Native or Alaskan American $\quad \square_{5}$ White, non-Hispanic

$\square_{2}$ Asian/Pacific Islander

$\square_{6}$ Multi-race/ethnicity (Please specify

$\square_{3}$ Hispanic/Latino

$\square_{7}$ Other (Please specify

$\square_{4}$ Black/African American 